\title{
MARKETING DE GUERRILHA COMO FERRAMENTA PARA DEFESA E PROMOÇÃO DE DIREITOS DAS MULHERES NEGRAS: O CASO MAJU E A CAMPANHA PUBLICITÁRIA DA ONG CRIOLA
}

\author{
LOPES, Amanda ${ }^{1}$ \\ CIRIBELI, João Paulo ${ }^{2}$ \\ MENDES, Wanderson de Almeida ${ }^{3}$ \\ MENDES, Wesley de Almeida ${ }^{4}$
}

\begin{abstract}
Recebido em: $2020.11 .19 \quad$ Aprovado em: $2021.04 .29 \quad$ ISSUE DOI: $10.3738 / 1982.2278 .3866$
RESUMO: O objetivo desta pesquisa foi identificar as estratégias para a escolha de comentários e analisar os resultados da campanha. A pesquisa classifica-se como básica e qualitativa. Foi feita uma entrevista com a diretora de comunicação da agência W3Haus, segundo a qual se conclui que os resultados com a campanha foram satisfatórios e conseguiram mostrar que as pessoas não estavam invisíveis na internet, podendo ser rastreadas e encontradas; além disso, a campanha teve grande repercussão na mídia nacional e internacional, que é uma das características do Marketing de Guerrilha.
\end{abstract}

Palavras-chave: Estratégias. Inovação. Publicidade.

\section{THE USE OF GUERRILHA MARKETING AS A TOOL FOR DEFENSE AND PROMOTION OF BLACK WOMEN'S RIGHTS: THE MAJU CASE AND THE CRIOLA NGO'S ADVERTISING CAMPAIGN}

SUMMARY: The objective of this research was to identify the strategies for choosing comments and to analyze the results of the campaign. The research is classified as basic and qualitative. An interview was made with the communication director of the agency W3Haus, according to which it was concluded that the results with the campaign were satisfactory and managed to show that people were not invisible on the internet, being able to be tracked and found; in addition, the campaign had a great repercussion in the national and international media, which is one of the characteristics of Guerrilla Marketing.

Keywords: Strategies. Innovation. Advertising.

\section{INTRODUÇÃO}

O marketing tradicional parece estar perdendo a força. Novas estratégias, como o marketing de guerrilha, estão conquistando profissionais da área e prometendo atingir o público alvo com maior intensidade. No início, essa estratégia de marketing era utilizada somente por pequenas empresas, considerando que o seu custo era menor que o marketing tradicional. As técnicas tradicionais não funcionam adequadamente num ambiente onde a sociedade e, por consequência, os consumidores são bombardeados com inúmeras informações e diversos tipos de

\footnotetext{
${ }^{1}$ Graduada em Administração pela FAGOC.

${ }^{2}$ Doutor em Administração. Professor da UNIFAGOC e Gestor Municipal de Convênios - GMC da Prefeitura Municipal de Guiricema.

${ }^{3}$ Doutorando e Mestre em Administração com concentração na área pública do Programa de Pós-Graduação em Administração da Universidade Federal de Viçosa (PPGADM/UFV). Membro da Sociedade Brasileira de Administração Pública. Membro do colegiado do curso de Administração da UNIFAGOC.

${ }^{4}$ Doutor e Mestre em Administração pela Universidade Federal de Viçosa.
}

Nucleus, v.18, n.1, abr.2021 
comunicação visual, por isso grandes empresas também aderiram a esse tipo de marketing para se destacar de maneira inovadora e criativa.

Além do baixo custo, o marketing de guerrilha gera mídia espontânea e na maioria das vezes gera uma comoção no público. Por esse motivo, as organizações não governamentais ONGs também buscam utilizar essas ferramentas para chamar a atenção da população para problemas críticos da sociedade com o objeto de cessá-los. Exemplo são as campanhas que enfatizam os problemas enfrentados por deficientes físicos, aquecimento global, dentre outros.

As ferramentas do marketing de guerrilha estão sempre acompanhadas de muita criatividade e poder de persuasão. Nesta pesquisa, serão listadas oito ferramentas específicas: Astrouturfing, ambush (marketing de emboscada), blog, eventos e patrocínios, guerrilha urbana, PR-stunt, balls marketing e marketing invisível.

Esta pesquisa foca na ferramenta denominada $P R$-stunt, pois é a que foi utilizada em uma campanha realizada pela ONG Criola ${ }^{5}$ junto à agência de publicidade e propaganda W3haus. Essa ferramenta é usada em campanhas que têm o objetivo de gerar boca a boca e mídia espontânea. Para isso, são feitas ações inusitadas, de maneira a chamar atenção do público.

Para a realização dessa campanha, a agência W3haus e a ONG Criola utilizaram outdoors, cujo conteúdo nele apresentado eram comentários racistas reais que foram postados na internet. Portanto, o objetivo da presente pesquisa é identificar as estratégias para a escolha de comentários racistas, e analisar os resultados da campanha da ONG Criola.

A campanha apresentada pela ONG Criola mostra os problemas enfrentados pelas mulheres negras na sociedade e as reais consequências do racismo virtual nas cidades brasileiras. Segundo a Central Nacional de Denúncias e Crimes Cibernéticos, eles recebem em média 2.500 denúncias por dia contendo evidências do crime de racismo. A ONG SaferNet Brasil, fundada em 2005, confirma que já recebeu e processou durante o período de atuação mais de 4 mil denúncias anônimas, envolvendo mais de 800 mil páginas (URLs) (SAFERNET, 2021). Levando em consideração esses dados e analisando o cenário brasileiro diante desse problema, a ação da agência W3haus e da ONG Criola busca amenizar esses números e conscientizar a população.

Diante do exposto, o problema da pesquisa se configura nas seguintes indagações: de que forma a empresa W3haus, junto à ONG Criola, utilizou a estratégia de marketing de guerrilha para impactar a população, como mecanismo de conscientização em relação a discriminação de mulheres negras? Quais as implicações geradas pela campanha?

\footnotetext{
${ }^{5}$ A CRIOLA é uma organização da sociedade civil fundada em 1992 e, desde então, conduzida por mulheres negras. CRIOLA define sua atuação a partir da defesa e promoção de direitos das mulheres negras em uma perspectiva integrada e transversal. Visamos a inserção de mulheres negras como agentes de transformação, contribuindo para a construção de uma sociedade fundada em valores de justiça, equidade e solidariedade, em que a presença e contribuição da mulher negra sejam acolhidas como um bem da humanidade.
}

Nucleus, v.18, n.1, abr.2021 


\section{REFERENCIAL TEÓRICO}

\subsection{Aspectos históricos e conceituais sobre o Marketing de Guerrilha}

Uma guerra não convencional - assim Dantas (2009) define "guerrilha", completando que a ação psicológica é a grande tática, pois faz com que os adversários que são considerados mais fortes e que visivelmente são dados como vencidos conseguem ser combatidos por adversários menores e mais fracos, usando principalmente a criatividade na criação de armas improvisadas ou até mesmo a maneira alternativa de utilizar as armas convencionais (LEVINSON, 2007).

O termo "guerrilha" vem do espanhol "guirrila", que quer dizer "pequena guerra". Esse termo surgiu no início do século XIX, quando as tropas de Napoleão invadiram a Espanha, que em combates irregulares tinham à sua frente a população (CAVALCANTE, 2003). Porém, Barboza (2007) afirma que o termo "guerrilha” teve início em 1965 no Vietnã, onde os Estados Unidos, mesmo com um alto poder destrutivo e centenas de armas modernas, perderam para os Vietnamitas, que tinham a sua frente uma minoria de combatentes junto a um arsenal visivelmente ultrapassado.

Em 1982, o publicitário norte-americano Levinson adaptou e trouxe para o mundo dos negócios as práticas de guerrilha bélica, com o intuito de mostrar, a pequenas empresas, novas táticas para concorrer com empresas maiores. O marketing de guerrilha nasceu com o propósito de fazer pequenos negócios sobreviverem a um mercado totalmente competitivo, utilizando estratégias mais baratas, focando na criatividade (CAVALCANTE, 2003).

A partir disso, surgiu um novo conceito de marketing, que procura maneiras diferenciadas de divulgação de produtos, marcas e serviços atingindo clientes potenciais. O marketing de guerrilha defende que uma campanha, quando planejada e bem executada, não precisa de grandes orçamentos para competir de maneira eficaz com empresas maiores (MAIA, 2012).

O marketing de guerrilha, assim como o marketing tradicional, trabalha os 4 Ps (produto, preço, praça e promoção), de forma a chamar a atenção do público com criatividade e diferenciação (DANTAS, 2009; MCCARTHY; PERREAIULT, 1997). Apesar de os 4 Ps serem utilizados pelo marketing de guerrilha, o P de promoção é mais recorrente (MCCARTHY, PERREAIULT, 1997). A promoção nada mais é do que as estratégias usadas pelas empresas para vender seu produto em meio a tantas opções que o mercado oferece, além de fazer com que o consumidor sempre se lembre da marca. Kotler e Keller (2005, p.136) afirmam que a "Promoção cobre todas as ferramentas de comunicação que fazem chegar uma mensagem ao público alvo". 


\subsection{Ferramentas utilizadas pelo marketing de guerrilha}

As ferramentas do marketing de guerrilha são utilizadas por empresas que têm como objetivo combater o concorrente ou apenas sobreviver ao mercado, de maneira barata e eficaz (ANDREAS, 2012). Nas palavras de Freire e Almeida (2006, p. 276), “a estratégia é atacar o consumidor de forma menos esperada possível, usando táticas de guerrilha bélica, que usa criatividade em vez de dinheiro".

As campanhas que utilizam como estratégia o marketing de guerrilha geralmente acontecem em locais não convencionais, como praças, cinemas e principalmente nas ruas. Por isso, a criatividade e a inovação são imprescindíveis em ações desse tipo.

Apesar de ter algumas características bem especificas em relação às ferramentas utilizadas e como elas são vistas e tratadas, o marketing de guerrilha tende a existir de forma sinérgica ao marketing tradicional, pois os dois tipos se incrementam positivamente (ANDREAS, 2012; SANTOS; ATHAYDES, 2008).

Diante do exposto, listam-se abaixo as oito ferramentas específicas utilizadas pelo marketing de guerrilha, que, quando são usadas de forma criativa, geram grande impacto, mídia espontânea e o famoso "boca a boca".

Astroturfing são ações que, mesmo parecendo um movimento espontâneo, foram pensadas e planejadas para promover uma marca, produto ou ideia. Geralmente são utilizados atores e figurantes (OLIVEIRA, 2009; HERNANDEZ, 2008). Maia (2012) descreve essa ferramenta como "uma provocação de movimentos espontâneos que tem uma causa associada a uma marca, promovendo barulho e disseminando mensagens que conseguem engajar um público específico".

Essas ações podem acontecer em grandes manifestações, em que um grupo de ativistas é infiltrado em prol de uma causa. A internet vem ajudando muito, pois facilita e viabiliza financeiramente a organização e o envolvimento de voluntários que têm interesse por uma causa ou uma marca (OLIVEIRA, 2009).

Ambush (marketing de emboscada) consiste em promover um produto ou marca de maneira criativa em eventos patrocinados pela concorrente. Essas ações se realizam obviamente sem a permissão dos organizadores e sem pagar as cotas de patrocínio. A emboscada pode até confundir o público em relação a quem é verdadeiramente o patrocinador do evento, minimizando os impactos das ações das empresas que pagaram (POSSAMAI, 2007).

Esse tipo de ação é muito utilizado em eventos esportivos. Um exemplo bem conhecido ocorreu na Copa de 1990, que tinha o patrocínio da Kaiser. Sua concorrente, a Brahma, investiu em torcida organizada, materiais promocionais e painéis. A empresa espalhou, por toda a torcida, 
grandes dedos que remetiam a seu slogan: “A número 1”. Além disso, pagou a alguns jogadores para levantarem o dedo indicador quando fizessem algum gol, em referência a sua campanha (MEISEN, 2007; PORTUGAL, 2014). Desse modo, o resultado foi mais favorável à Brahma do que para a Kaiser, que era a patrocinadora oficial do evento.

Blogs são ferramentas com grande potencial interativo e de baixo custo, que podem ser usadas para campanhas publicitárias. As empresas anunciam em blogs que atingem o público alvo da empresa, possibilitando uma comunicação eficaz.

Possamai (2007) compartilha que os blogs são grandes formadores de opinião e que as pessoas são consideravelmente influenciando por eles na hora da compra de um produto, serviço ou ideia. Essa ferramenta está ficando cada vez mais e forte e influente, além de ser mais interativa e rápida.

Apesar de ser uma ação muito utilizada pelo marketing tradicional, eventos e patrocínios podem ser bem eficazes quando é usada com originalidade e criatividade, gerando grande visibilidade na mídia (OLIVEIRA, 2009).

Possamai (2007) ainda ressalta que a participação de empresas em eventos e o investimento em patrocínio constituem uma ferramenta de guerrilha muito importante e, mesmo que seja uma tática já muito normal e corriqueira, é possível inovar.

A Red Bull, com a ideia de associar a marca a qualidades como coragem, força e ousadia, apostou em patrocínio de atletas e eventos esportivos, inovando na sua forma de chamar atenção do público alvo:

[...] a marca cria outras ações de menor tamanho, mas grande em ousadia e repercussão: O Red Bull Paper Wings, por exemplo, é uma competição de aviõezinhos de papel feita entre estudantes de faculdades e universidades do mundo todo. Se o objetivo é impactar, que tal colocar um carro de Fórmula 1 na nas ruas de São Paulo? Foi o que fez a empresa em 2006.Por falar em ações menores, porém impactantes, a Red Bull realizou ano passado o Red Bull Gravity Challenge, que consiste em jogar um ovo de uma altura de 15 metros sem que ele quebre ao chegar ao chão. Esta ação já é tradicional e chegou à PUC-RJ em outubro passado. O desafio dos alunos era construir um projeto que fosse capaz de evitar qualquer rachadura no ovo após acertá-lo no alvo fixado no chão. (TERRA, 2009).

O objetivo da guerrilha urbana é interagir de maneira criativa e inovadora com objetos já existentes no ambiente. Geralmente esse tipo de ação gera muito impacto, pois é diferente do que se vê no dia a dia, e costuma chamar atenção; dessa maneira, torna-se quase impossível não ser atingido por essas mensagens (HERNANDEZ, 2008; MAIA, 2012).

O PR-Stunt nada mais é do que a criação de situações inusitadas em determinados locais, com o objetivo de gerar o boca-boca e a mídia espontânea, pois essas ações, aliadas a um trabalho de relações públicas, proporcionam mensagens em diversos meios (MAIA, 2012). Portanto, Hernandez (2008) ressalta que, para realizar ações desse tipo, é necessário ter ideias inovadoras e 
um grande grau de criatividade, que, além de atingir pessoas próximas, poderão também ter proporções mundiais.

Um caso conhecido de $P R$-Stunt foi a recente campanha realizada pela ONG Criola com a agência W3haus, objeto de estudo desta pesquisa. A ação utilizou outdoors de forma e conteúdo diferentes, com o objetivo de chamar a atenção do público e da mídia para um problema enfrentado pela sociedade: o racismo.

Segundo Figueiredo (2005), o outdoor possui um grande impacto visual, por seu tamanho e flexibilidade geográfica. A junção de imagens e textos em um outdoor, de forma criativa e inovadora, faz com que o anúncio aproveite melhor desse meio. A localização também é imprescindível para uma ação eficaz.

O Balls Marketing promove ações arriscadas e exige coragem para ser realizada. Por esse motivo, consegue atrair a imprensa e diversas pessoas, que ficam curiosas e intrigadas (OLIVEIRA, 2009)

O Marketing invisível são ações feitas em determinados locais, de maneira que não pareça uma estratégia de marketing. Por exemplo: um pouco antes do lançamento do documentário do Amyr Klink no canal National Geographic, tiveram a ideia de distribuir fotos de sua viagem em um conhecido cinema. Do lado de fora do envelope havia escrito seu nome com o seu telefone. Ao encontrar esses envelopes, as pessoas ligavam para o número que lá estava, com a intenção de devolver. Porém para a surpresa de todos, a ligação "caia" na caixa postal que tinha uma mensagem na voz de Amyr dizendo que não estava em casa, pois estava finalizando seu documentário que iria estrear nos próximos dias.

\subsection{Marketing de guerrilha e ações de responsabilidade social: mulher/ racismo/ preconceito}

Empresas e, principalmente, organizações não governamentais vêm utilizando o marketing de guerrilha para promover ações ligadas à responsabilidade social. Essas ações geralmente têm o objetivo de chamar a atenção das pessoas para problemas críticos da sociedade. Algumas empresas se aproveitaram disso para vincular sua marca a esse tipo de ação, que de certa forma incrementa positivamente sua imagem (ANDREAS, 2012).

A busca pela excelência e eficiência no mercado acaba não sendo mais uma junção do cálculo do custo benefício, produtividade e expansão de vendas. Os critérios para definir o sucesso de uma empresa passam a incorporar outros caminhos, que vão além da economia e dizem respeito à vida social (CAPPELLIN; GIULIANI, 1999; KOTLER; KARTAJAYA; SETIAWAN, 2010), embora haja ONGs que vivem em prol disso e têm como objetivo conscientizar pessoas e amenizar problemas da sociedade. 
Adotando essa filosofia, as empresas buscaram planejar de maneira inovadora campanhas que fazem referência a problemas do dia a dia e que frequentemente são ignorados, como o preconceito racial existente desde o tempo da escravidão, quando era usado para justificar o domínio de certos grupos sobre outros.

No Brasil em 2015, aproximadamente 53,9\% dos brasileiros se declararam pardos ou pretos (IBGE, 2015). As mulheres que se encaixam nessa porcentagem, por conta do seu gênero e raça, sofrem ainda mais as consequências do racismo.

\footnotetext{
À medida que a mulher negra ascende, aumentam as dificuldades especialmente devido à concorrência. Em serviços domésticos que não representam prestígio não há concorrência e consequentemente as mulheres negras têm livre acesso e é nesse campo que se encontra o maior número delas. A população negra trabalha, geralmente, em posições menos qualificadas e recebe os mais baixos salários. A discriminação racial na vida das mulheres negras é constante; apesar disso, muitas constituíram estratégias próprias para superar as dificuldades decorrentes dessa problemática. (SINGER, 1998. p. 25).
}

As mulheres negras na sociedade sofrem o pré-conceito racial, que nada mais é do que um pré-julgamento baseado apenas em sua raça/etnia, sem razão objetiva. Normalmente esse julgamento é expresso através de piadas, injurias e apelidos (LOPES, 2001).

Vem crescendo o nível de consciência de que o racismo precisa ser denunciado e combatido, mas ainda é preciso lutar para que a igualdade entre etnias se estabeleça na sociedade. $\mathrm{O}$ ato de discriminar pessoas de outras raças não é herdado geneticamente. Isso acontece por conta de opiniões pré-estabelecidas pela sociedade, impostas pelo meio e pela educação (SANT'ANA, 2001; TINOCO, 2009).

As redes sociais são palcos de preconceito racial, devido à falsa impressão de ser um local livre e as pessoas poderem falar o querem. Muitas ofensas estão tomando proporções nos noticiários, levando as pessoas a debaterem o problema. Por isso, o número de denúncias de racismo disparou a partir de 2014. Segundo relatório da ONG SaferNet, mais de 86,5 mil casos de ódio a negros e outras etnias foram divulgados em 17.291 sites, representando um aumento de $34,15 \%$ em relação a 2013. As páginas denunciadas somaram 58.717, das quais 7 mil foram tiradas do ar (SAFERNET, 2021).

\section{METODOLOGIA}

Para responder à questão levantada, procedeu-se à consulta bibliográfica como base para um estudo de caso. Quanto à natureza, a pesquisa classifica-se como básica e, quanto ao tratamento dos dados, qualitativa, uma vez que busca o aprofundamento e de que forma e como ela é compreendida pelas pessoas. Quanto aos fins, a pesquisa se classifica como descritiva. Esse tipo de pesquisa pode ser entendido como um estudo de caso: após a coleta de dados, é realizada 
uma análise das relações entre as variáveis para uma posterior determinação dos efeitos resultantes em uma empresa, sistema de produção ou produto.

Foi analisado o caso: "Racismo virtual. As consequências são reais" - uma ação criada pela ONG Criola e agência de publicidade e propaganda W3haus, que divulgaram comentários racistas feitos no Facebook sobre a jornalista Maju em outdoors nas regiões onde vivem os ofensores.

A coleta de dados ocorreu através do uso de e-mail, realizando uma entrevista semiestruturada com a responsável pela comunicação da agência W3haus. As informações também foram coletadas por meio de e-mail enviado à Diretora da ONG Crioula e por meio de ligação telefônica, também à Diretora. A conversa por telefone foi gravada para que os pontos importantes pudessem ser extraídos e incluídos na íntegra, tal e qual foi dito pela entrevistada, minimizando assim duplicidade de sentido. O e-mail foi utilizado para obter informações gerais da campanha, enquanto a ligação utilizada para obter detalhes das ações promocionais.

Após a realização da coleta de dados, foi feita a transcrição das entrevistas, a fim de organizar e analisar as informações obtidas pelos entrevistados. Por fim, foi feita uma análise descritiva das entrevistas, onde se discute pontos fundamentais para a pesquisa.

\section{RESULTADO E DISCUSSÃO}

Nesta sessão são apresentados o contexto da campanha e o processo de criação, e principalmente as implicações geradas.

O racismo é presente em nossa sociedade desde sempre, e várias ações já foram feitas por meios de TVs, rádios, revistas, com o objetivo de alertar para esse problema. Ataques a pessoas pretas são recorrentes, porém um caso que chamou atenção e teve uma grande repercussão foi o da apresentadora Maria Júlia Coutinho, que apresenta um quadro no Jornal Nacional, a qual sofreu ataques racistas em sua rede social após publicar uma foto. A apresentadora - apelidada por seu colega de trabalho, William Bonner, de Maju - teve o apoio de outros apresentadores, os quais, para apoiá-la, lançaram a hashtag \#somostodosmaju. Bonner, durante o Jornal, disse:

Eu e a Renata [Vasconcellos] falamos em nome de todos os colegas da Globo, que, é claro, também repudiaram as agressões absurdas. \#SomosTodosMaju, né, Renata?

A polícia de São Paulo identificou entre os autores um menor de 15 anos, o qual foi ouvido e liberado em seguida. $O$ adolescente vai responder por ato infracional e pode sofrer alguma medida sócio educativa. O crime, caracterizado como injúria e previsto no artigo 140 do Código Penal, consiste em ofender a dignidade ou o decoro de alguém "na utilização de 
elementos referentes a raça, cor, etnia, religião, origem ou a condição de pessoa idosa ou portadora de deficiência" (BRASIL, 1989). Há várias penas possíveis para o racismo, entre elas prisão e multa; porém, o crime de racismo não tem direito a fiança.

Conforme apontado pela diretora de comunicação da agência W3haus nos dizeres que seguem, pode-se verificar que, após ter conhecimento do "caso Maju”, toda a agência se indignou e resolveu tomar uma atitude. Assim, surgiu a campanha "Racismo virtual, as consequências são reais".

A ideia de fazer a campanha começou com os primeiros ataques racistas contra a apresentadora Maju. Surgiu uma indignação geral do pessoal da agência. Somamos nossos esforços, nosso potencial como agência de publicidade e facilidade em pôr o tema na mídia, e conseguimos colocar a campanha no ar.

Após a ideia de criar uma campanha que mostrasse que ninguém está invisível nas redes sociais, deu-se início ao processo criativo. Para isso, precisavam de algo que chamasse a atenção e que possibilitasse fixar, na mente do público-alvo, a mensagem desejada.

Por não ter nenhum tipo de briefing de cliente, tivemos muita liberdade para criar. Tivemos o envolvimento de quase todas as áreas da agência, com várias ideias pertinentes, até chegarmos a um modelo que achávamos que funcionaria bem. A W3haus colocaria a campanha na rua, independente de termos cliente. Então apresentamos a nossa ideia para a ONG Criola, que se interessou muito e abraçou a causa. Até hoje temos a ONG como cliente pró-bono.

Para chamar a atenção das pessoas, observa-se que, como ferramenta de marketing de guerrilha, foi utilizado o PR-Stunt, que é a criação de situações inusitadas que geram mídia espontânea (POSSAMAI, 2007)

No caso da campanha, colocaram outdoors, que é uma mídia comum, porém com os comentários racistas perto da casa do próprio agressor, o que gerou mídia espontânea esperada. A campanha teve grande repercussão no Brasil e também no exterior. Vários meios de comunicação internacionais, como a conceituada revista de Marketing Contagious, noticiaram a ação publicitária, e isso fez com que a agência recebesse quatro solicitações para exportar a campanha para outros países. Teve como consequência, também, um aumento de tráfego no site Criola, o qual passou a ser acessado por 153 países. A agência W3haus recebeu diversos prêmios pela campanha, entre eles o maior prêmio da Web no mundo, o Webby Awardys. Também foi reconhecida na Contagious, uma das maiores revistas de publicidade do mundo.

Segundo a diretora da agência, os motivos pela utilização do outdoor se configuram na seguinte justificativa

Outdoor é a mídia que mais vai ao encontro da proposta da campanha: mostrar que as ofensas são virtuais, mas que as consequências podem ser reais. Queríamos tirar o assunto do anonimato da internet e estampar de uma forma que todos pudessem ver. Até quem não está na internet. 
Em relação ao tempo de exposição das peças, sabe-se que algumas datas podem influenciar na divulgação; nesse caso, como é uma campanha que retrata o racismo, a semana do dia 20 de novembro, Dia da Consciência Negra, poderia ser uma opção de divulgação; porém, a diretora alega que não houve qualquer critério:

A exposição dos outdoors varia muito. Tivemos casos de exposição de três dias e outros de duas semanas. A campanha foi iniciada logo após a formatação, independente de data.

As artes foram expostas em lugares estratégicos, ou seja, perto da casa dos agressores. Para isso, a agência executou um trabalho de mapeamento, utilizando as ferramentas de geolocalização. A propósito, um dos critérios para a escolha dos comentários a serem colocados nos outdoors foi esse. As primeiras cidades a receberam a ação foram: Americana (SP), Feira de Santana (BA) e Vila Velha (ES).

Selecionamos diversos comentários. Alguns causaram tanta repulsa em todo time W3haus que achamos melhor nem publicar. Levamos em consideração o conteúdo e localização das pessoas. Gostaríamos de ter a campanha vinculada em todo país, para termos um grande alcance e colocar o tema em pauta.

Todos os outdoors da campanha utilizaram-se do mesmo estilo de formatação; o que os diferencia são as frases neles colocadas.

Primeiramente, percebe-se um outdoor com frases e o nome da campanha logo abaixo, com as marcas da agência de publicidade 3Whaus e ONG Criola, do lado direito, na parte inferior da arte (ver Figura 1, Figura 2, Figura 3 e Figura 4).

Observa-se que as frases são colocadas em um fundo que remete à rede social Facebook, onde se encontram a foto e o nome do usuário - nesse caso, borrados, para que não se identifique o autor; botões como favoritar e compartilhar; e também a localização da postagem.

As frases utilizadas nas artes são postagens reais feitas por usuários do Facebook, na página da apresentadora Maju. Escrita de forma pejorativa e racista, chama a atenção, impacta e gera o famoso "boca a boca", consequentemente atraindo a mídia orgânica ou inboundmarketing, considerando-se, dessa forma, uma ação de marketing de guerrilha. 
Figura 1: De onde vieram alguns agressores

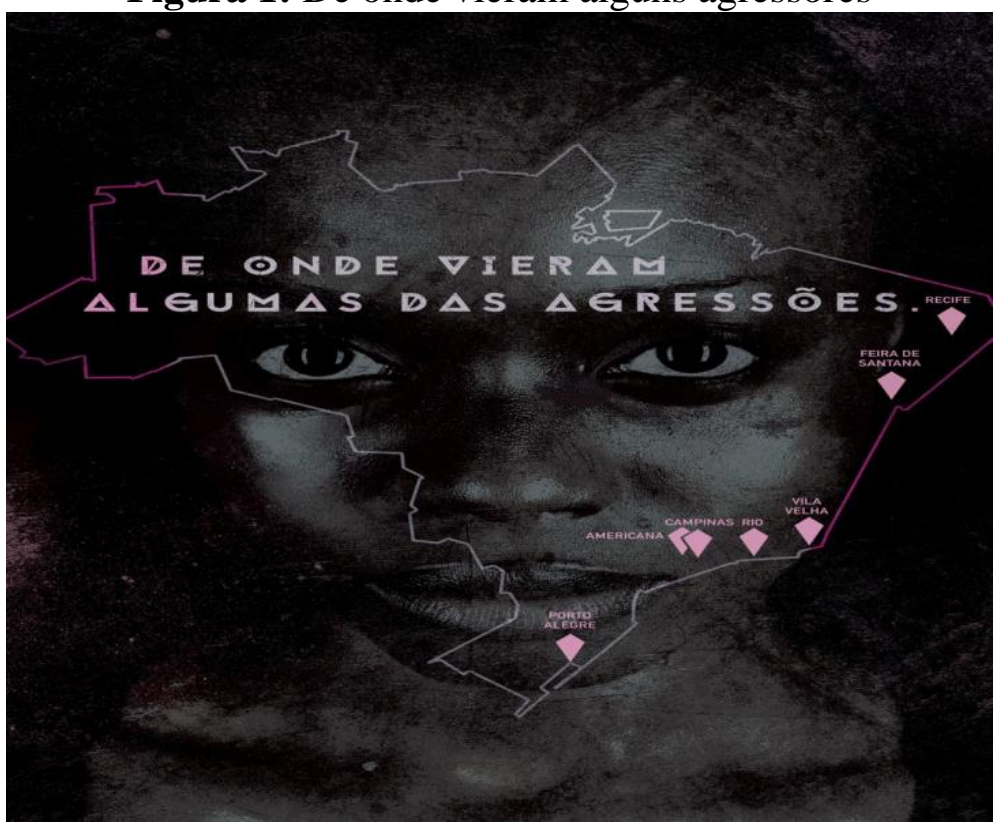

Fonte: arquivo da agência W3Haus.

Figura 2: Outdoor localizado em Americana-São Paulo

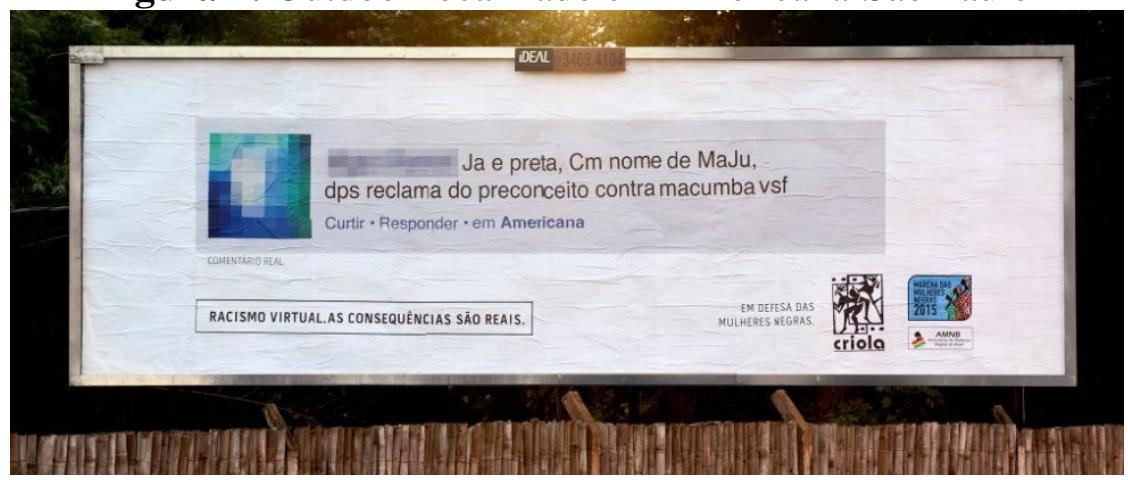

Fonte: arquivo da agência W3Haus.

Figura 3: Outdoor localizado em Feira de Santana-Bahia

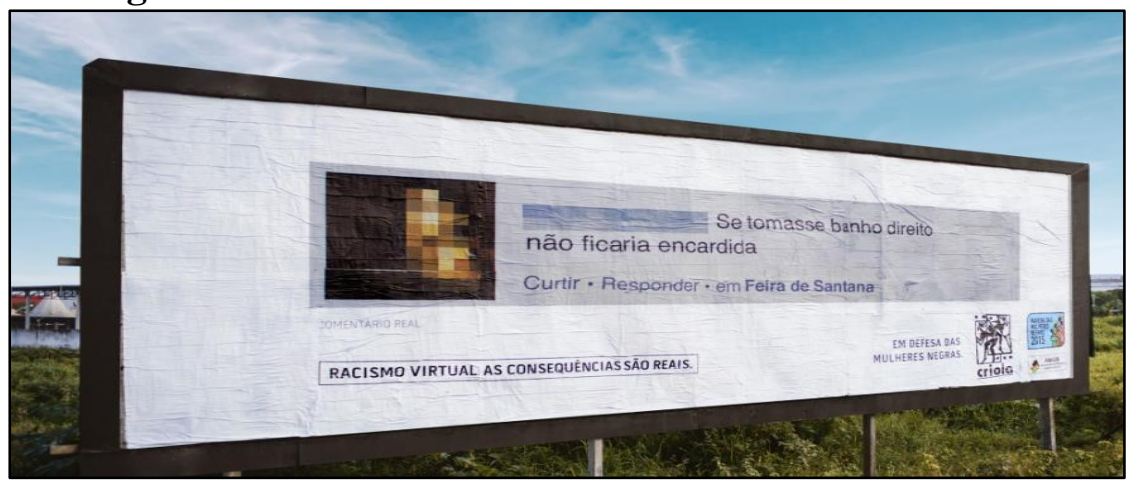

Fonte: arquivo da agência W3Haus. 
Figura 4: Outdoor localizado em Vila Velha-Espírito Santo

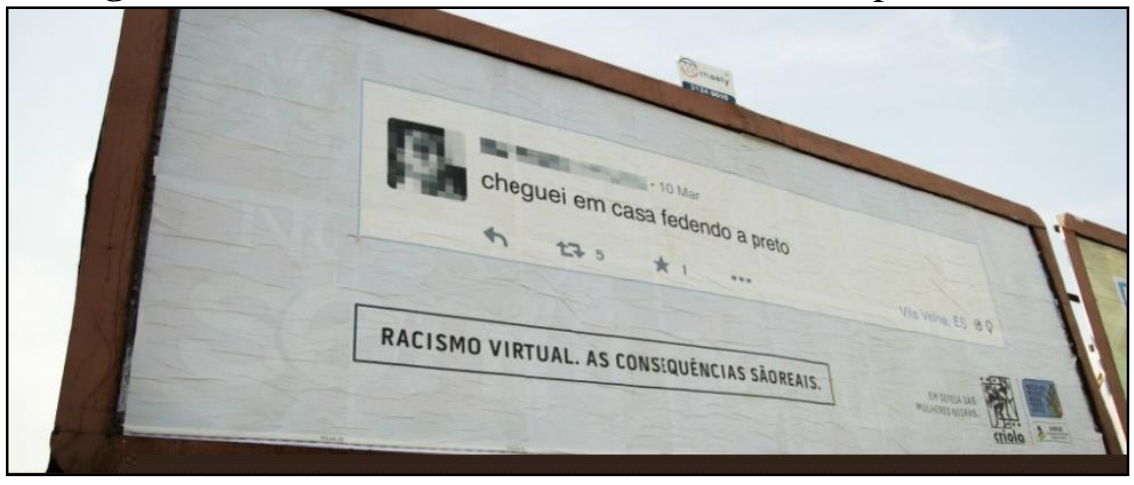

Fonte: arquivo da agência W3Haus.

Essas ações de marketing de guerrilha se caracterizam pelo baixo custo. Para Levinson (2007, p.1): "Funciona, porque é simples de entender, fácil de implementar e ridiculamente barato".

Esta foi uma campanha pró-bono, sem custos. Tivemos parceiros que cederam espaço em mídia, além de produtoras, que cederam o trabalho. A W3haus arcou somente com alguns custos para conseguir colocar a campanha no ar.

Indagada se a campanha ajudou ou teve alguma influência na punição dos agressores, a diretora afirmou:

O nosso objetivo não era este. Pelo contrário. Queríamos conscientizar as pessoas sobre o assunto. Conseguimos mostrar que as pessoas não se tornam invisíveis na internet.

Essa conscientização relatada por Daniela precisa se tornar recorrente na sociedade, já que a internet é considerada "terra de ninguém". É preciso mostrar a essas pessoas que elas podem ser vistas, identificadas e encontradas. Isso fez com que $83 \%$ os infratores excluíssem suas contas em redes sociais e um deles, arrependido, decidiu dar seu depoimento em vídeo, desculpando-se com uma pessoa negra, como forma de retratação perante a sociedade:

Um amigo meu me mostrou e eu me assustei muito. Eu pude perceber o quão racista eu tinha sido realmente. A pessoa que leu isso daqui, como ela se sentiu. Eu acho que vocês negros são muito mais fortes do que tudo que as pessoas falam a respeito de vocês de forma negativa. Eu acho que vocês negros são muito mais fortes do que tudo que as pessoas falam a respeito de vocês de forma negativa.

Embora seja pretensão esperar que uma campanha resolva os problemas de discriminação no Brasil servindo de reforço e estímulo para promover essa redução. A diretora da agência, confirma:

Ainda não houve redução na discriminação contra os negros, principalmente mulheres negras. É um assunto que tem que estar sempre trabalhando na sociedade.

Ela ainda citou um caso recente de discriminação contra Leslie Jones, uma das protagonistas do filme Caça Fantasmas. 


\section{CONSIDERAÇÕES FINAIS}

Este estudo possibilitou observar que hoje, com a internet e a saturação de imagens e propagandas vistas no dia a dia, o marketing de guerrilha surgiu como uma alternativa ágil e dinâmica para as empresas sobressaírem no mercado. Considerada uma estratégia rápida, criativa e ousada, possibilita uma disputa justa entre empresas de diversos tamanhos.

O propósito do trabalho foi pesquisar sobre o marketing de guerrilha e apresentar mais detalhes sobre a campanha "Racismo virtual, as consequências são reais", criada pela agência W3Haus junto a ONG Criola.

Percebe-se que cresce cada vez mais o preconceito contra negros, e isso se torna mais evidente quando se trata de mulheres negras. $\mathrm{O}$ caso de racismo vivido pela apresentadora Maju, a qual recebeu em sua página comentários pejorativos de cunho racista, é um dos mais conhecidos recentemente.

A ação publicitária teve como objetivo mostrar que as pessoas não estão invisíveis nas redes sociais, portanto podem sim serem vistas e punidas. Para isso, utilizaram outdoors que, embora seja uma mídia tradicional, é a que mais vai ao encontro do público. O que classifica a campanha como guerrilha é o conteúdo exposto e a localização das peças, pois foram colocados outdoors perto da casa dos agressores, com o comentário racista feito por eles na rede social da apresentadora Maju, o que gerou indignação em grande parte das pessoas que os viram.

Outro fato importante a ser relatado é que, mesmo com o marketing de guerrilha, considerado como uma forte ferramenta, segundo a diretora de comunicação da agência não houve redução da discriminação contra mulheres negras, até porque não se consegue conscientizar as pessoas. Além de se tornar uma campanha reconhecida mundialmente, e trazer o tema para o dia a dia, a agência e a ONG conseguiram mostrar que as pessoas podem ser vistas na rede social, já que os comentários foram localizados e os outdoors foram dispostos estrategicamente perto da casa dos agressores.

Tendo como base o objetivo da campanha, que é mostrar que as pessoas não estão invisíveis nas redes sociais - os resultados foram satisfatórios: um dos agressores se reconheceu em um outdoor perto de sua casa e a campanha foi muito divulgada, ganhando diversos prêmios.

Para a elaboração da pesquisa, teve-se como limitação a entrevista com a diretora da agência, a princípio a ideia era de um bate-papo por meio do Skype, porém devido ao tempo disponível na agencia, a mesma sugeriu uma entrevista mais direta, onde as perguntas foram elaboradas antes e mandadas por e-mail.

Futuramente recomenda-se um estudo mais apurado sobre uma possível diminuição ou aumento dos casos de Racismo Virtual. 


\section{REFERÊNCIAS}

ANDREAS, D. L. M. Marketing de guerrilha: um estudo sobre o uso de estratégias de marketing baixo custo para pequenas empresas. Presidente Prudente: FIAET, 2012.

BARBOZA, N. A. Arte, cultura, história. Rio de Janeiro: [s.n], 2007.

BRASIL, Lei $\mathrm{n}^{\circ} 7.716$, de 5 de janeiro de 1989. Define os crimes resultantes de preconceito de raça ou de cor.

CAPPELLIN, P.; GIULIANI G. Compromisso social no mundo dos negócios. Boletim do Ibase, n. 11 , fev. 1999.

CAVALCANTE, F. Faça marketing de guerrilha: soluções criativas, baratas e eficazes para o sucesso de pequenas empresas. Belém, PA: Labor, 2003.

DANTAS, E. B. A propaganda de guerrilha: uma nova alternativa para posicionar marcas.

Biblioteca Online de Ciências da Comunicação. 2009. p. 1-14.

FIGUEIREDO, C. Redação publicitária: sedução pelas palavras. São Paulo: Thomson Learning, 2005.

FREIRE, M. V.; ALMEIDA, D.R. Ouro olímpico: a história do marketing dos aros. Rio de Janeiro: Casa das palavras - COB, 2006.

HERNANDEZ, T. F. M. Artigo Científico. Marketing de guerrilha e intervenção urbana: a luta simbólica por atenção no espaço urbano. Palhoça, 2008. Disponível em:

<http://www.carosouvintes.org.br/blog/wp-content/uploads/15.mktgguerrilha.pdf >. Acesso em: 04 maio 2014.

IBGE. Sistema IBGE de Recuperação Automática - SIDRA, 2015. Disponivel em: <http://www2.sidra.ibge.gov.br/>. Acesso em: 04 abr. 2021.

KOTLER, P.; KELLER, K. L. Administração de marketing. 12. ed. São Paulo: Pearson Prentice Hall, 2005.

KOTLER. P.; KARTAJAYA, H.; SETIAWAN, I. Marketing 3.0: as forças que estão definindo o novo marketing centrado no ser humano. Rio de Janeiro: Elsevier, 2010.

LEVINSON, J. C. Criatividade de Guerrilha. São Paulo: Mauad, 2007.

LOPES, V. N. Afro-descendência: Pluralidade Cultural precisa e deve abordar a questão do negro brasileiro. Revista do Professor, Rio Grande do Sul, n.67, p.21-25, 2001.

MAIA, A. K. A. Artigo Científico. Mais com menos: marketing de Guerrilha, uma alternativa a publicidade tradicional. Mar. 2012. Disponível em:

<http://www.insite.pro.br/2013/Janeiro/marketing_guerrilha_publicidade.pdf>. Acesso em: 04 abr. 2020.

MCCARTHY, E.; PERREAULT, William. Marketing essencial: uma abordagem gerencial e global. São Paulo: Atlas, 1997. 
MEISEN, A. M. G. Análise do conhecimento do marketing de guerrilha e aplicação de suas ferramentas por parte das agências de publicidade de Blumenau. $105 \mathrm{f}$. Monografia (Graduação em Comunicação Social - Publicidade e Propaganda) -Universidade Regional de Blumenau, Blumenau, 2007.

OLIVEIRA, C. F. O marketing de guerrilha e sua aceitação em Juiz de Fora. Juiz de Fora: CESJF, 2009. 155 f. Monografia (Graduação em Comunicação Social - Publicidade e Propaganda) Centro de Ensino Superior de Juiz de Fora, Juiz de Fora, 2009.

PORTUGAL, M. 10 ações de marketing de emboscada no esporte. 2014. Disponível em: <https://exame.com/marketing/10-acoes-de-marketing-de-emboscada-em-torneios-esportivos/>. Acesso em: 04 abr. 2020.

POSSAMAI, A. P. O marketing de guerrilha em pequenas empresas de Bento Gonçalves.78 f. Monografia (Graduação em Publicidade e Propaganda) - Universidade de Caxias do Sul, Caxias do Sul, 2007.

SAFERNET. SaferNet Brasil, 2021. Disponível em:

$<$ https://new.safernet.org.br/?field_subject_value=All\&field_type_value=All\&page=1 >. Acesso em: 02 abr. 2021.

SANT’ANA, A. H. O cotidiano e a história. 6. ed. São Paulo: Paz e Terra, 2001.

SANTOS, J. M; ATHAYDES, A. A ética nas ações do marketing de guerrilha. In: CONGRESSO DE CIÊNCIAS DA COMUNICAÇÃO NA REGIÃO SUL, 11. INTERCOMSociedade Brasileira de Estudos Interdisciplinares da Comunicação. [Anais...] Guarapuava, 2008.

SINGER, P. Globalização e desemprego: diagnósticos e alternativas. São Paulo: Contexto, 1998.

TERRA, T. Red Bull investe em esportes radicais e ações de risco para dar asas ao desejo dos consumidores. Mundo do Marketing, 2009. Disponível em:

$<$ https://www.mundodomarketing.com.br/cases/7053/red-bull-investe-em-esportes-radicais-eacoes-de-risco-para-dar-asas-ao-desejo-dos-consumidores.html>. Acesso em: 10 out. 2020.

TINOCO, M. D. Preconceito e discriminação com as mulheres negras da E.J.A. Porto Alegre: UFRS, 2009. 43 f. Monografia (Pós-graduação em Especialização e Integração da Educação Profissional à Educação Básica na Modalidade de Jovens e Adultos). 